\title{
Originals
}

\section{Effects of Dietary Fibre Supplementation in Stable and Labile Insulin-dependent Diabetics}

\author{
L. H. Monnier, Marie J. Blotman, C. Colette, Marie P. Monnier, and J. Mirouze \\ Department of Metabolic and Endocrine Diseases, Hôpital Saint-Eloi, Montpellier, France
}

Summary. Seven stable and 10 labile insulin-dependent diabetic patients were submitted to 2 dietary regimens which were given in random order and maintained for 10 to 15 days. During one period ("control") patients were given their usual diets. During the other period patients received a fibre supplemented diet ("test"). The fibre supplementation was calculated to provide $1 \mathrm{~g}$ dietary fibre per $15 \mathrm{~g}$ available carbohydrate. For each period, diabetic control was estimated from: (i) daily glycosuria; (ii) $\%$ glycosylated haemoglobin, (iii) insulin requirements, (iv) frequency of hypoglycaemic episodes and (v) circadian blood glucose levels. Dietary fibre supplementation resulted in: (i) decreased glycosuria in both stable $(12.8 \pm 5.6 \mathrm{~g} /$ day vs $25.5 \pm 6.9 \mathrm{P}<0.01)$ and labile diabetics $(35.8 \pm 10.5 \mathrm{~g} /$ day vs, $52.5 \pm$ $7.1, \mathrm{P}<0.02$ ); (ii) a significant decrease in blood glucose at $1430 \mathrm{~h}(\mathrm{P}<0.02)$ in stable and at $1430 \mathrm{~h}$ $(\mathrm{P}<0.05)$ and $2030 \mathrm{~h}(\mathrm{P}<0.01)$ in labile diabetics. The percentage of glycosylated haemoglobin was identical in stable $(10.8 \pm 1.0 \%)$ and labile diabetics $(10.7 \pm 1.0)$ and was slightly depressed with the fibre supplemented diet $(9.5 \pm 0.8$ and $9.3 \pm 0.6$ respectively). The mean blood glucose during the control period was not significantly different in stable (186士 $28 \mathrm{mg} / 100 \mathrm{ml}$ ) and labile diabetes $(221 \pm 24 \mathrm{mg} /$ $100 \mathrm{ml}$ ) and did not change significantly with fibre treatment. The results show that the control of stable and labile diabetes is improved to a similar degree by dietary fibre. This effect results mainly from a decrease in post prandial hyperglycaemia after lunch and dinner.

Key words: Dietary fibre, stable diabetes, labile diabetes, glycosylated haemoglobin, glycaemic control.
Epidemiological surveys have suggested that high fibre diets reduce the frequency of diabetes mellitus $[1,2]$ and there is some evidence that the supplementation of normal meals with certain types of dietary fibre such as pectins, guar and hemicelluloses results in a decrease of post-prandial hyperglycaemia $[3,4$, $5,6]$. The course of insulin-dependent diabetes is characterized by rapid fluctuations in blood glucose [7] and frequently by adverse responses to insulin therapy (such as hypoglycaemic episodes). In order to obtain optimum diabetic control, the dosage of subcutaneous insulin must be carefully adjusted each day and long term dietary measures observed. The need both to reduce the percentage of available carbohydrates in the diet of diabetic patients and to avoid nutrients containing concentrated refined carbohydrates has been long recognized, but despite these measures many patients continue to show poor glycaemic control. Dietary fibre has been reported to benefit control in "chemical diabetes" [8], non-insulin dependent diabetes [3] and insulin-dependent diabetes $[9,10,11,12]$. Here we report a study comparing the effects of high fibre diets on diabetic control in patients with stable or labile insulin-dependent diabetes.

\section{Materials and Methods}

\section{Subjects}

Seventeen insulin-requiring diabetic patients, 22-71 years (mean, 48 years) were studied after their informed consent had been obtained. The mean $\%$ ideal body weight of the patients \pm SD was: $102 \pm 9 \%$ (range: $84-120 \%$ ) at the start and $103 \pm 9 \%$ $(84-118 \%)$ at the end of the study. Mean ideal body weight was estimated from the tables of the Metropolitan Life Insurance Co. The patients were separated into labile and stable diabetics by calculating the mean amplitude of glycaemic excursions (Mage) [7, $13,14]$ 
L. H. Monnier et al.: Dietary Fibre in Diabetes

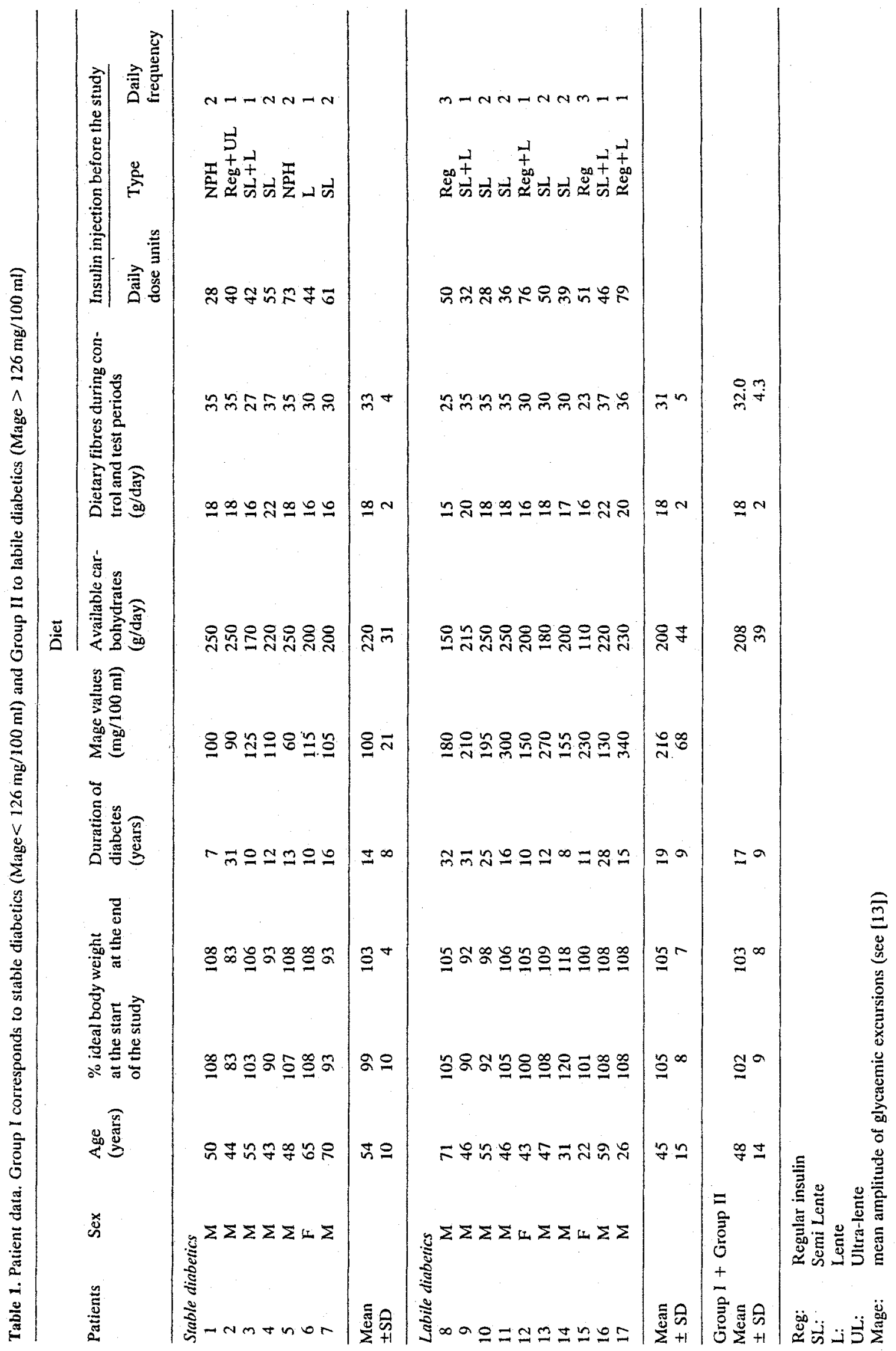


Table 2. Comparison of the criteria of diabetic control. Control and test periods correspond respectively to periods with and without dietar fiber supplementation. Mean blood glucose is the average of circadian variations obtained from blood samples at $0000,0400,0800,0930$ $1200,1400,1830$ and $2030 \mathrm{~h}$. Glycosuria corresponds to the average total daily excretion of glucose for each period

\begin{tabular}{|c|c|c|c|c|c|c|c|}
\hline \multirow{2}{*}{$\begin{array}{l}\text { Type of diabetes } \\
\text { Period of investigation } \\
\text { No. of patients }\end{array}$} & & \multicolumn{2}{|l|}{ Stable } & \multicolumn{2}{|l|}{ Labile } & \multicolumn{2}{|c|}{ Labile + Stable } \\
\hline & & $\begin{array}{l}\text { Control } \\
7\end{array}$ & $\begin{array}{l}\text { Test } \\
7\end{array}$ & $\begin{array}{l}\text { Control } \\
10\end{array}$ & $\begin{array}{l}\text { Test } \\
10\end{array}$ & $\begin{array}{l}\text { Control } \\
17\end{array}$ & $\begin{array}{l}\text { Test } \\
17\end{array}$ \\
\hline \multirow{2}{*}{$\begin{array}{l}\text { Mean blood glucose } \\
\text { concentration }(\mathrm{mg} / 100 \mathrm{ml})\end{array}$} & Mean & 186 & 171 & 221 & 192 & 206 & 184 \\
\hline & SEM & 28 & 22 & 24 & 24 & 18 & 17 \\
\hline \multirow[t]{2}{*}{ Glycosuria (g per day) } & Mean & 25.5 & $12.8^{c}$ & 52.5 & $35.8^{b}$ & 40.4 & $26.0^{c}$ \\
\hline & SEM & 6.9 & 5.6 & 7.1 & 10.5 & 6.2 & 7.1 \\
\hline \multirow{2}{*}{ Glycosylated haemoglobin (\%) } & Mean & 10.8 & $9.5^{\mathrm{a}}$ & 10.7 & $9.3^{\mathrm{a}}$ & 10.8 & $9.4^{a}$ \\
\hline & SEM & 1.0 & 0.8 & 1.0 & 0.6 & 0.7 & 0.5 \\
\hline \multirow{2}{*}{$\begin{array}{l}\text { Insulin requirements } \\
\text { (units per day) }\end{array}$} & Mean & 51 & 52 & 49 & 50 & 50 & 51 \\
\hline & SEM & 6 & 7 & 6 & 6 & 4 & 5 \\
\hline \multirow{2}{*}{$\begin{array}{l}\text { No. of hypoglycaemic } \\
\text { episodes per week }\end{array}$} & Mean & 1.6 & 2.5 & 2.7 & 3.3 & 2.2 & 3.0 \\
\hline & SEM & 0.6 & 1.0 & 0.8 & 0.6 & 0.5 & 0.5 \\
\hline
\end{tabular}

${ }^{\mathrm{a}} \mathrm{P}<0.1,{ }^{\mathrm{b}} \mathrm{P}<0.02,{ }^{\mathrm{c}} \mathrm{P}<0.01$ compared with appropriate control

All results are given as mean \pm SEM. Statistical differences, established by Wilcoxon signed ranktest, are only indicated when significant

Seven patients with Mage values lower than $126 \mathrm{mg} / 100 \mathrm{ml}$ (Group I) were considered stable. The 10 other patients (Group II) had Mage values greater than $126 \mathrm{mg} / 100 \mathrm{ml}$ and were considered to be labile. In order to avoid any interference from treatment the patients selected for the study received no medication other than their insulin. Additional clinical details are given in Table 1.

\section{Protocol}

Each patient was submitted to a dietary trial divided into 2 successive periods ranging from 10 to 15 days. All patients were hospitalized for the entire study Throughout the investigation (i. e during the two periods) the content of the diet in available carbohydrate was supervised by the dietitians and maintained at a value which was constant and similar to the normal intake of the patient. Available carbohydrates provided 40 per cent of total calories (range: 110 to $250 \mathrm{~g}$ per day), while lipids and proteins accounted respectively for 45 and 15 per cent. Meal times were standardized and comprised 3 main meals (breakfast, lunch and dinner) and 3 snacks (mid-morning, mid-afternoon and bed time).

Control Period. The patients were submitted to a low fibre intake [15] ranging from 15 to $23 \mathrm{~g}$ and corresponding to their usual intake (Table 1). The dietary fibre intake was estimated from food composition tables [16].

Test Period. The patients received the same diet as above supplemented with a dietetic preparation derived from wheat bran. The test bread was given in $2.3 \mathrm{~g}$ units (Cerefibres Gressins, supplied by Meram Lab. France) each of them providing 8 Calories, $1 \mathrm{~g}$ of available carbohydrate and $1 \mathrm{~g}$ of dietary fibre. The number of units given to each patient was calculated to provide an additional intake of $1 \mathrm{~g}$ of dietary fibre for $15 \mathrm{~g}$ of available carbohydrate contained in the food. Alternatively, the available carbohydrates provided by the test bread were substracted from the regular diet in order that the intake of available carbohydrates during the two periods was similar. Thus a patient fed $150 \mathrm{~g}$ of available carbohydrates during the control period was supplemented with $10 \mathrm{~g}$ of dietary fibre, i. e 10 units of test bread, during the test period. During the latter period the patient received respectively $140 \mathrm{~g}$ of available carbohydrate from his regular diet and $10 \mathrm{~g}$ from the test bread. The intakes of available carbohydrates and dietary fibres are detailed for all patients in Table 1 for each dietary sequence. The order of taking control and test diets was randomized.

Diaberic Control for each patient was estimated in the following ways. (i) Glycosuria was determined every day by Clinitest tablets (Ames $\mathrm{Co}$ ) on total $24 \mathrm{~h}$ urine collections, using the usual scale: 0 , $1 / 4,1 / 3,3 / 4,1$ and $2 \%(\mathrm{~g} / 100 \mathrm{ml})$. When glucose concentrations were higher than $2 \mathrm{~g} / 100 \mathrm{ml}$, calculations were made on results obtained from diluted urinary samples. The total glucose excretec every day was then averaged for each period. (ii) The percentage of total glycosylated haemoglobin $\left(\mathrm{Hb} \mathrm{A}_{1}\right)$ was measured at the end of each period by chromatographic separation using the Isolat system based on the methodology of Schnek et al. [17] (coefficien of variation: $2 \%$ ); (iii) The patient's insulin requirements were recorded. (iv) The frequency of hypoglycaemic episodes was ex. pressed as number per week. (v) The circadian pattern of blood glucose (Neocuproine Auto Analyzer) by regular timed blooc sampling during fasting (at $0000,0400,0800,1200$ and $1830 \mathrm{~h}$ ) and post prandial periods (at 0930,1400 and $2030 \mathrm{~h}$ ) was measured over the last day of each dietary sequence.

Statistical Analysis. All results are given as mean \pm SEM. Data were compared by the Wilcoxon signed ranking test which doe: not require normal distribution and large sample sizes.

\section{Results}

Glycosuria was markedly and significantly lower with fibre supplementation for both groups (Table 2).

Glycosylated haemoglobin was similar in labile $(10.7 \pm 1 \%)$ and stable diabetics $(10.8 \pm 1 \%)$ when receiving their usual diet. As shown in Table 2 a slight drop at the $10 \%$ level of statistical significance $(\mathrm{P}<0.1)$ was observed in both groups of patients after dietary fibre supplementation.

Insulin requirements in both groups $\mathrm{I}$ and II remained unchanged whether patients were under dietary fiber supplementation or not (Table 2). 


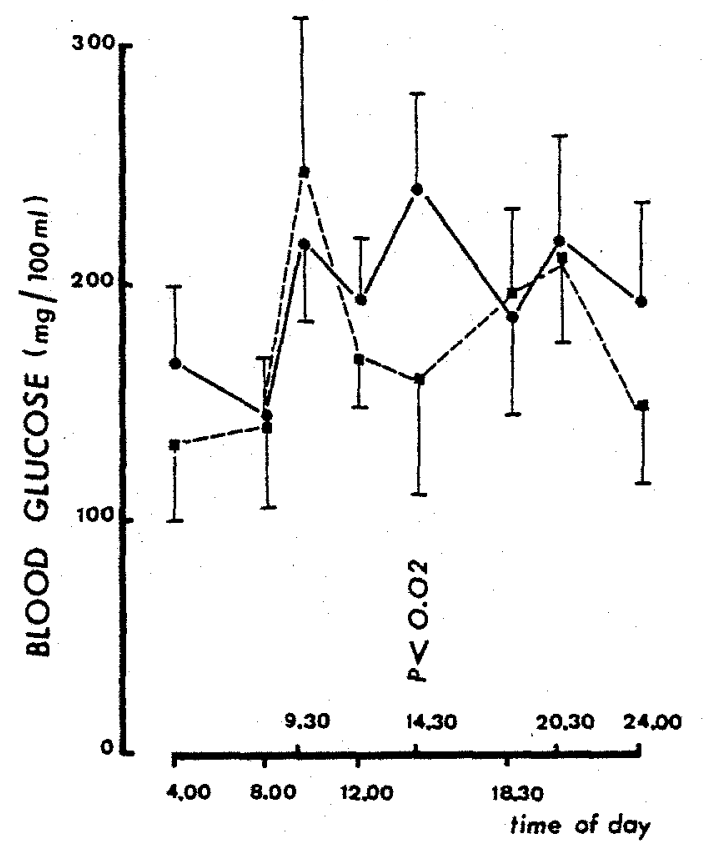

Fig. 1. Diurnal patterns of blood glucose concentrations in 7 stable

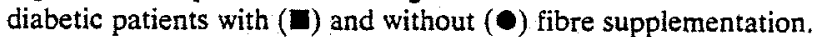
Meals were given at 0800,1200 and $1900 \mathrm{~h}$. Snacks were given at 1000,1600 and $2200 \mathrm{~h}$. The Wilcoxon signed ranking test is used for statistical comparisons

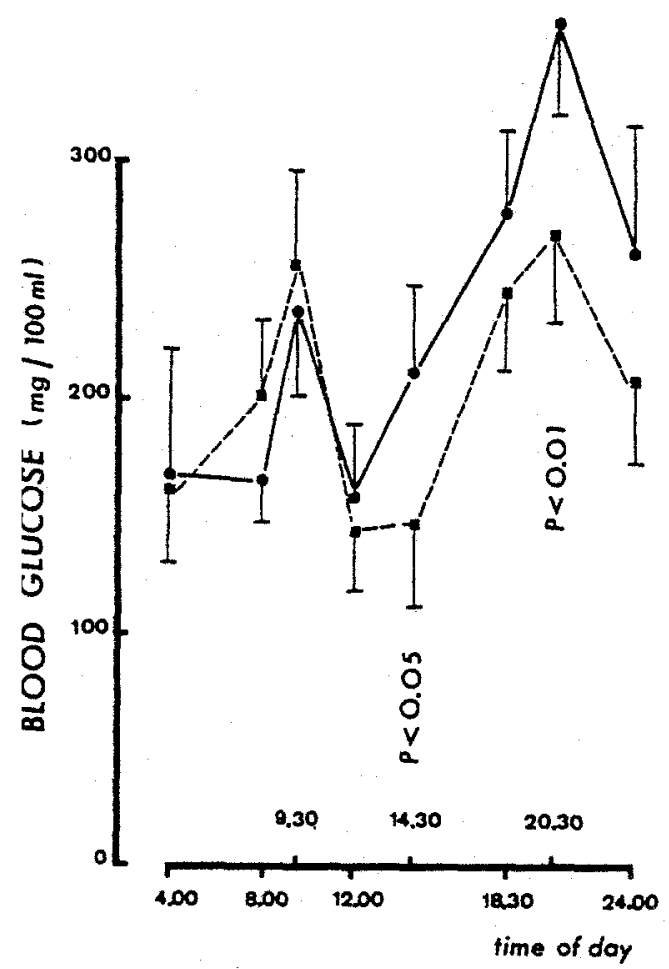

Fig. 2. Diurnal patterns of blood glucose concentration in 10 labile diabetic patients with (E) and without $(\bullet)$ fibre supplementation. Meals were given at 0800,1200 and $1900 \mathrm{~h}$. Snacks were given at 1000,1600 and $2200 \mathrm{~h}$. The Wilcoxon signed ranking test is used for statistical comparisons
The number of hypoglycaemic episodes per week was identical during the two periods, whether patients had stable or labile diabetes.

The circadian patterns of blood glucose concentrations are shown on Figure 1 and 2 for patients with stable and labile diabetes respectively. The statistical analysis indicates that fasting blood glucose concentrations were similar whether patients were supplemented or not with dietary fibre. In stable diabetics post-prandial glucose levels at $1430 \mathrm{~h}$ were significantly lower during the high fibre period compared to the control period (Fig. 1). In labile diabetics a significant diminution in post-prandial glucose levels was noted at 1430 and $2030 \mathrm{~h}$ during fibre supplementation (Fig. 2). In both groups similar blood glucose values were observed after breakfast.

The mean blood glucose, i. e the average of glycaemic circadian variations was identical in both groups and during both periods.

\section{Discussion}

From the present study, it appears that post-prandial rises in blood glucose are significantly blunted by dietary fibre supplementation after lunch and dinner in labile diabetics, and after lunch in stable diabetics. This slight improvement in post-prandial hyperglycaemia is accompanied in both types of diabetes by a significant and similar fall in daily glycosuria, while insulin requirements remained unchanged. The slight decrease in percent glycosylated haemoglobins observed in both groups of patients tends to confirm that the carbohydrate homeostasis of insulin-requiring diabetics is improved by high tibre diets. Similar results have been previously observed by other authors in insulin-requiring diabetics $[9,10,11,18]$, but the present data indicate that labile and stable diabetics are improved to a similar, although small, degree by dietary fibre supplemented diets.

The beneficial effect of fibre is usually attributed either to slower gastric emptying or to formation of unabsorbable complexes with available carbohydrates in the gut lumen $[3,4,12]$. Therefore it has been suggested that these two properties might result both in delayed absorption of carbohydrates, and in reduction of the absolute quantity absorbed. The present study seems to indicate that absorption of calories and sugar into the blood stream was not reduced by dietary fibers since the patients did not exhibit any change in mean insulin-requirement, frequency of hypoglycaemia or body weight whether they were supplemented or not. However in other studies, it has been observed that fibre supplementation resulted in a significant fall of patient's insulin 
requirements $[9,18,19]$. When insulin doses were kept constant and similar under low and high fibre diets, as in Miranda's study [11], the number of hypoglycaemic episodes was significantly increased during the high fibre period. The discrepancies between these results and ours might be due to the fact that we added less fibre to our diets ( 23 to $37 \mathrm{~g}$ of dietary fibre daily i. e 8 to $16 \mathrm{~g}$ of crude fibre) than Miranda (20 g crude fibre daily) [11], and Jenkins ( $25 \mathrm{~g}$ guar gum daily) [9]. It seems therefore possible that the very high fibre diets used by these authors might not only have delayed but also reduced the absorption of carbohydrates.

Recent studies suggest that the quality of fibre may be as important as the quantity. Thus high viscosity preparations such as pectin and guar seem to have a considerable post prandial hypoglycaemic effect $[4,8,20]$ in contrast to cellulose and its lowviscosity derivatives which do not [20]. The fibre supplementation used in the present study was a wheat bran preparation. Hemicelluloses, which are the most abundant fibre components of bran are in many ways similar to guar and pectin. Our study shows that bran is effective, at least in the short term, and has the advantage over pectin and guar of greater patient acceptibility.

Fibre supplementation lowered the glycosylated haemoglobulin levels to the same extent in stable and labile diabetics. Furthermore, during the control (low fibre) period, the mean blood glucose was identical in stable and labile diabetes. Thus it appears that the wide and frequent glycaemic excursions found in labile diabetics are associated with mean blood glucose concentrations and glycosylation rates similar to those observed in stable diabetics with mild sustained hyperglycaemia. These findings are in agreement with the concept that glycosylation of haemoglobins depends both on the duration and degree of blood glucose elevation $[21-24]$. Therefore, although glycosylated haemoglobin levels are a useful indicator of hyperglycaemia over prolonged periods, they obviously do not help in assessing the stability or lability of diabetes mellitus [25].

$\mathrm{HbA}_{1}$ concentrations fell after only a short period of fibre supplementation. The glycosylation of haemoglobin is, however, considered to be a slow and non reversible process, characterised by a progressive accumulation of $\mathrm{HbA}_{1}$ through the 120 daylife span of the circulating red cells. Thus concentrations of $\mathrm{HbA}_{1}$ usually decrease only after a delay of 1 or 2 months following improved blood glucose control. For that reason, the decrease in $\mathrm{HbA}_{1}$ seen under fibre supplementation in the present study must reflect either a rapid fall in $\mathrm{HbA}_{1}$ production, i. e a dramatic improvement in diabetic control, or a reversibility of the glycosylation process. Our data seems support the latter hypothesis and we suggest with others $[26,27]$ that haemoglobin glycosylation is in part reversible.

Several conclusions can be drawn from the present study. First, our results confirm that dietary fibre supplementation improves to some extent diabetic control of insulin-dependent diabetics. Second, beneficial effects are obtained with the addition of moderate amounts of fibre. The use of moderate supplementation rather than high fibre diets, which might result in long term adverse side effects, may therefore be recommended although changes were small. Third, stable and labile diabetes are improved to a similar degree be dietary fibre.

Acknowledgements. The authors wish to thank Doctors E. Cartry and N. Sultan and Y. Vierne, for their skilled technical assistance.

\section{References}

1. Burkitt DP, Trowell HC (1975) Refined carbohydrate foods and disease. Some implications of dietary fibre. Academic Press, New York

2. Trowell HC (1975) Dietary fiber hypothesis of the etiology of diabetes mellitus. Diabetes 24: 762-765

3. Jenkins DJA, Goff DV, Leeds AR, Alberti KGMM, Wolever TMS, Gassuli MA, Hockaday TDR (1976) Unabsorbable carbohydrates and diabetes: decreased post prandial hyperglycaemia. Lancet I: 172-174

4. Jenkins DJA, Leeds AR, Gassull MA, Cochet B, Alberti KGMM (1977) Decrease in post prandial insulin and glucose concentrations by guar and pectin. Ann Intern Med 86: 20-23

5. Goulder. TJ, Alberti KGMM, Jenkins DA (1978) Effect of added fiber on the glucose and metabolic response to a mixed meal in normal and diabetic subjects. Diabetes Care 1: 351-355

6. Munoz JM; Sandstead HH, Jacob RA (1979) Effects of dietary fiber on giucose tolerance of normal men. Diabetes 28 : 496-502

7. Mirouze J, Collard F (1974) Continuous blood glucose monitoring in brittle diabetes. In: Malaisse WJ, Pirart J (eds) Diabetes. Excerpta Medica, Amsterdam, p 546-559

8. Monnier L, Pham TC, Aguirre L, Orsetti A, Mirouze J (1978) Influence of indigestible fibres on glucose tolerance. Diabetes Care 1; 83-88

9. Jenkins DJA, Hockaday TDR, Haworth T, Apling EL, Wolever TMS, Leeds AR, Bacon S, Dilawari J (1977) Treatment of diabetes with guar gum. Reduction in urinary glucose loss in diabetics. Lancet II: 779-780

10. Anderson JW, Ward K (1978) Long term effects of high-carbohydrate, high-fiber diets on glucose and lipid metabolism: a preliminary report on patients with diabetes. Diabetes Care 1: $77-82$

11. Miranda PM, Horwitz DL (1978) High fiber diets in the treatment of diabetes mellitus. Ann Intern Med 88: 482-486

12. Anderson JW, Lin Chen WJ (1979) Plant fiber. Carbohydrate and lipid metabolism. Am $J$ Clin Nutr 32: 346-363

13. Service FJ, Molnar GD, Rosevear JW, Ackerman E, Gatewood LC, Taylor WF (1970) Mean amplitude of glycemic excursions, a measure of diabetic instability. Diabetes 19: $644-655$ 
14. Molnar GD, Marien GJ, Hunter AN, Harley CH (1979) Methods of assessing diabetic control. Diabetologia 17:5-16

15. Bringham S, Cummings JH, McNeil NI (1979) Intakes and sources of dietary fiber in the British population. Am J Clin Nutr 32: 1313-1319

16. Southgate DAT, Bailey B, Collinson E, Walker AF (1976) A guide to calculating intakes of dietary fibre. $J$ Hum Nutr 30 : 303-313

17. Schnek AG, Schroeder WA (1961) The relation between the minor components of whole normal human adult hemoglobin as isolated by chromatography and starch block electrophoresis. J Am Chem Soc 83: 1472-1478

18. Douglass JM (1975) Raw diet and insulin requirements. Ann Intern Med 82: 61-62

19. Anderson JW, Midgley WR, Wedman B (1979) Fibre and diabetes. Diabetes Care 2: 369-379

20. Jenkins DJA, Wolever TMS, Leeds AR, Gassull MA, Haisman P, Dilawari J, Goff DV, Metz GL, Alberti KGMM (1978) Dietary fibres, fibre analogues and glucose tolerance: importance of viscosity. $\mathrm{Br}$ Med J I: $1392-1394$

21. Koening RJ, Peterson CM, Kilo C, Cerami A, Williamson JR (1976) Hemoglobin $A_{\mathrm{Ic}}$ as an indicator of the degree of glucose intolerance in diabetes. Diabetes 25: 230-232

22. Paulsen EP, Koury M (1976) Hemoglobin $A_{1 c}$ levels in insulin dependent and independent diabetes mellitus. Diabetes 25 [Suppl 2]: 890-896
23. Bunn HF, Gabbay KH, Gallop PM (1978) The glycosylation of hemogiobin: relevance to diabetes. Science 200: 21-27

24. Spicer KM, Allen RC, Hallett D, Buse MG (1979) Synthesis of hemoglobin $A_{\mathrm{lc}}$ and related minor hemoglobins by erythrocytes. J Clin Invest $64: 40-48$

25. Gonen B, Rochman H, Rubenstein AH, Tanega SP, Horwitz DL (1977) Hemoglobin $A_{1 c}$ an indicator of the metabolic control of diabetic patients. Lancet II: 734-736

26. Vlachokosta F, Koenig R, Cahill GF, Soeldner JS (1980) Evidence of reversibility of hemoglobin $(\mathrm{Hb}) \mathrm{A}_{\mathrm{lc}}$. Diabetes 29 [Suppl 2 ]: 22

27. Bolli $G$, Cartechini MG, Compagnucci $P$, Santeusanio $F$, Massi-Benedetti M, Calabrese G, Puxeddu A, Brunetti P (1980) Modification of glycosylated haemoglobin concentration during artificial endocrine pancreas treatment of diabetics. Evidence of a short-term effect on $\mathrm{HbA}_{1(\mathrm{a}+\mathrm{b}+\mathrm{c})}$ levels. Diabetologia 18: $125-130$

Received: November 28, 1979 , and in revised form: July 29,1980

Prof. L. Monnier

Department of Metabolic and Endocrine Diseases

Hopital Saint-Eloi

F-34059 Montpellier Cedex

France 